Revista Brasileira de Farmacognosia Brazilian Journal of Pharmacognosy 21(3): 510-517, May./Jun. 2011

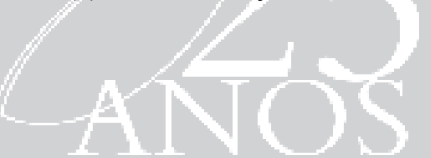

Article

Received 1 Aug 2010

Accepted 27 Sep 2010

Available online 18 Mar 2011

Keywords:

Maytenus ilicifolia

Cassia angustifolia

co-processed extract

flowability

tablets

ISSN 0102-695X

doi: 10.1590/S0102-695X2011005000038

\section{Co-processed extracts of Cassia angustifolia and Maytenus ilicifolia for production of high load tablets}

\author{
Verônica M. L. Alves, ${ }^{1}$ Lívia C. L. Sá-Barreto, ${ }^{2}$ Gustavo H. B. \\ Souza, ${ }^{1}$ Marcílio S. S. Cunha-Filho ${ }^{* 2}$
}

${ }^{I}$ Escola de Farmácia, Universidade Federal de Ouro Preto, Brazil,

${ }^{2}$ Instituto de Ciências da Saúde, Campus Universitário de Sinop, Universidade Federal do Mato Grosso, Brazil.

\begin{abstract}
The aim of this study was to investigate the feasibility of a co-processing technique for improving the manufacturing properties of Maytenus ilicifolia (Schrad.) Planch., Celastraceae, and Cassia angustifolia Vahl, Fabaceae, extracts in order to obtain tablets containing a high dose of such extracts. An experimental mixture design was used to optimise the formulation composition. Flowability parameters, such as compressibility index, time flow and angle of repose, were determined. Additional important industrial parameters, such as granulometry, bulk density and moisture stability, were also studied. The results demonstrated that co-processing technique was able to improve the flowability of vegetal extracts, making these materials suitable for a direct compression process. The contour plots revealed that formulations with a higher amount of lactose produced the best flow results as well as a larger particle size and a greater bulk density. Tablets from co-processed extracts containing lactose as majority diluent showed appropriate physical-chemical characteristics and presented a more stable moisture sorption behaviour compared to commercial gelatine capsules.
\end{abstract}

\section{Introduction}

Medicinal plants are used therapeutically all around the world and are an important aspect of various traditional medicine systems. During the past few decades, the application of phytotherapy has increased, even in industrialized countries (WHO, 2007). Despite the great potential of herbal medicine, research indicates a lack of information among health professionals about phytotherapy, with the result that this therapeutic resource has remained relatively obscure (Veiga Junior, 2008). Scant literature is available about the preparation and formulation of phytotherapeutics, which explains why most of these products are homemade to date.

A tablet form is the preferred medium of pharmaceutical scientists and clinicians. The ease of manufacturing, low cost, convenience of administration and accurate dosing capabilities make tablets a popular and versatile dosage form (Gohel \& Jogani, 2005). Nevertheless, the most common vehicles for medicinal plants are capsules and oral liquids (Vieira et al., 2010).

Dried extracts from medicinal plants are often used as active components in solid dosage forms because of their high stability. However, these products generally present deficient rheological properties, inadequate compressibility and high sensitivity to atmospheric moisture, resulting in difficult direct compression (Souza et al., 2007). The flow behaviour of pharmaceutical powders determines important properties of solid dosage forms; in some cases, the success or failure of a product has hinged on its flow behaviour during manufacturing (Prescott \& Barnum, 2000).

Co-processing methods are often used to improve rheological and compression characteristics of pharmaceutical excipients (Cunha-Filho \& SáBarreto, 2009). These techniques transform a small, cohesive, poorly flowable powder into a flowable and directly compressible material by engineering particles without affecting the structure at a molecular level. Co-processing is achieved by combining two or more materials by an appropriate process, such as co-grinding or agglomeration, resulting in a product with superior properties compared to the simple physical mixtures of their components (Gohel \& Jogani, 2005).

Recent studies with Phyllanthus niruri extracts were successful in obtaining granules for compression process. Souza et al. (2007) used eudragit E as granulating agent in order to improve flowability and moisture sorption behaviour of granules and Spaniol et al. (2009) investigated the use of granules containing 
spray-dried extracts together with microcrystalline cellulose to produce tablets using both eccentric and rotary presses. Zhao et al. (2010) reported the feasibility of superfine grinding technique in improve physicalchemical properties of Astragalus membranaceus powders. Others studies highlight the importance of the use of excipients during spray-drying process, to obtain dried extracts with better flow characteristics (Oliveira \& Petrovick, 2010).

The purpose of this work was to investigate the feasibility of an agglomeration technique to produce co-processed extracts using pharmaceutical excipients in order to improve rheological properties, compaction behaviour and moisture stability. To this end, two plants were selected - Cassia angustifolia Vahl, Fabaceae, and Maytenus ilicifolia (Schrad.) Planch., Celastraceae, that are used medicinally worldwide (Silva et al., 2004; Santos-Oliveira et al., 2009).

\section{Material and Methods}

\section{Material}

The plant materials used in this study were commercial samples obtained from All Chemistry do Brasil $^{\circledR}$. Dried leaf extracts from Maytenus ilicifolia (Schrad.) Planch. Celastraceae (MI), lot 33695, and Cassia angustifolia Vahl (CA), Fabaceae, lot 33884, were used.

The excipients used were microcrystalline cellulose PH 101 (MCC), lactose monohydrate (lactose), polyvinylpyrrolidone (PVP), magnesium stearate and maize starch (starch) purchased from Henrifarma ${ }^{\circledR}$. All solvents were of analytical grade.

\section{Angle of repose and flow time}

The angle of repose was assessed by the fixed funnel method (Staniforth, 2005). Briefly, $50 \mathrm{~g}$ of each sample was poured into the funnel, forming a conical pile. The angle of repose was measured by the internal angle subtended by the surface of a heap of powder against the plane that supported it and was then measured with a protractor. Flow time was established by determining the time the samples took to flow from a standard funnel. All measurements were taken in ten replicate.

\section{Bulk density}

The bulk density was the density including pores and interparticle voids. Powder samples were levelled carefully (without compacting) into a $100 \mathrm{~mL}$ cylinder. The bulk density was calculated from the ratio of the weight of the sample to the bulk volume. This procedure was carried out in triplicate.

\section{Compressibility index and Hausner index}

The compressibility index and Hausner index were determined using bulk density and tap density values (RFE, 2005). Approximately $50 \mathrm{~g}$ of powder was gently poured into a $100 \mathrm{~mL}$ graduated cylinder and the initial volume was recorded. Then it was tapped in a series of 250 times until a constant volume was reached, and the final volume was recorded. The tapped density was calculated as the ratio between the sample weight and the final volume (Carr, 1965). All experiments were performed in triplicate. The compressibility and Hausner indices were calculated using the equations below:

Compressibility Index $=100 \times(\delta \mathrm{t}-\delta \mathrm{a}) / \delta \mathrm{t}$

Hausner Index $=\delta \mathrm{a} / \delta \mathrm{t}$

where $\delta \mathrm{a}$ is the bulk density of material freely settled and $\delta \mathrm{t}$ is the tapped density of material.

\section{Particle size analysis}

In order to determine the size particle distribution of dried extracts and co-processed samples, a sieve analysis was performed in an automatic sieve shaker using 710, 590, 500, 420, 210, 149 and $88 \mu \mathrm{m}$ sieves in triplicate. The linearization of the Gaussian particle size distribution was developed using probits statistical analysis (Pasqualoto et al., 2005). The mean cumulative particle size dates were converting into probit values using probit spreadsheet. The particles' mean diameter and standard deviation were calculated from probit regression.

\section{Co-processing method}

The procedure chosen to co-process the extracts was the agglomeration process by wet granulation. Mixtures of dry extract and excipients were blended in a $\mathrm{V}$ mixer for $20 \mathrm{~min}$. Batches of $100 \mathrm{~g}$ were wetted with an aqueous solution of PVP $15 \%(\mathrm{w} / \mathrm{v})$, manually blended and strained using an oscillating granulator, sieved through $2.5 \mathrm{~mm}$ pores. The granules were dried in a circulating air oven at $25{ }^{\circ} \mathrm{C}$ for $24 \mathrm{~h}$. The dried granules were calibrated through a sieve of $1.5 \mathrm{~mm}$ using an oscillating granulator and stored.

\section{Experimental design}

The formulations were elaborated according to a mixture design. The effect of varying composition on flow properties, particle size and bulk density were studied using a simplex lattice design without constraints. This design included ten experimental points. Mass fractions of fillers (MCC, lactose and starch) in a formulation were used as variables. The runs of the experimental design and the composition of the batches are shown in Table 1. 
Experiments were carried out in a random order to avoid the incidence of systematic error.

Table 1. Component proportions of simplex lattice design.

\begin{tabular}{cccccc}
\hline Formulation & $\begin{array}{c}\text { Starch } \\
(\%)\end{array}$ & $\begin{array}{c}\text { MCC } \\
(\%)\end{array}$ & $\begin{array}{c}\text { Lactose } \\
(\%)\end{array}$ & $\begin{array}{c}\text { Dried } \\
\text { extract (\%) }\end{array}$ & $\begin{array}{c}\text { PVP } \\
(\%)\end{array}$ \\
\hline 1 & 49 & 0 & 0 & 49 & 2 \\
2 & 0 & 49 & 0 & 49 & 2 \\
3 & 0 & 0 & 49 & 49 & 2 \\
4 & 24.5 & 24.5 & 0 & 49 & 2 \\
5 & 24.5 & 0 & 24.5 & 49 & 2 \\
6 & 0 & 24.5 & 24.5 & 49 & 2 \\
7 & 16.3 & 16.3 & 16.3 & 49 & 2 \\
8 & 32.6 & 8.2 & 8.2 & 49 & 2 \\
9 & 8.2 & 32.6 & 8.2 & 49 & 2 \\
10 & 8.2 & 8.2 & 32.6 & 49 & 2 \\
\hline
\end{tabular}

The best fitting mathematical model was selected for each response. The results were fitted with polynomial functions of MCC, lactose and starch content by means of stepwise multiple regression analysis. The validation of the model was performed through analysis of variance with a level of significance 0.05 and through the coefficient of determination $\left(\mathrm{R}^{2}\right)$. Adequate precision (APrecision) was calculated as a signal of noise ratio relative to the associated error. A ratio greater than four is desirable (Anderson \& Whitcomb, 2005). All statistical calculation and graphic plots were performed using the software Design-Expert version $8^{\circledR}$.

\section{Preparation of tablets}

Selected co-processed extracts were mixed with $0.5 \%$ magnesium stearate in a $\mathrm{V}$ mixer for $5 \mathrm{~min}$ and were incorporated into tablet form. Batches of $100 \mathrm{~g}$ were compressed into tablets on a Primel Faber ${ }^{\circledR}$ eccentric press using a compression force of $30 \mathrm{kgF}$. For the CA co-processed extract, a $13 \mathrm{~mm}$ die and flat-faced punches were used; for MI co-processed extracts, a $14 \mathrm{~mm}$ die and flat-faced punches were employed. The loading depth of the press was adjusted to obtain tablets of CA and MI extracts with a theoretical weight of $400 \mathrm{mg}$ and $500 \mathrm{mg}$, respectively, in order to keep the dose at that which is used commercially for each plant.

\section{Physical-chemical characterization of tablets}

Tablet formulations were subjected to the following tests according to The United States Pharmacopeia (USP, 2008).

\section{Weight}

The weights of twenty randomly selected tablets were determined individually and the mean weight and coefficient of weight variation were calculated.

\section{Hardness}

The hardness of ten randomly selected tablets was obtained using an OFF-TEC Galileo ${ }^{\circledR}$ apparatus. The mean hardness and coefficient of hardness variation were calculated.

\section{Friability}

Tablet friability was measured as the percentage of weight loss of twenty randomly-selected tablets tumbled in an Ética ${ }^{\circledR}$ friabilator working at $100 \mathrm{rpm}$ for 5 $\min$.

\section{Disintegration time}

Disintegration time was measured in water at 37 ${ }^{\circ} \mathrm{C}$ in an Ética ${ }^{\circledR}$ disintegration tester. For each formulation, six randomly selected tablets were tested.

\section{Water sorption assay}

Hygroscopicity of selected tablets was compared with capsules containing dried extracts using the experimental model described by Callahan (Callahan et al., 1982). The amount of $400 \mathrm{mg}$ and $500 \mathrm{mg}$ of CA and MI dried extracts, respectively, were weighted and manually filled into size zero hard gelatine capsules. The moisture sorption properties of samples were determined gravimetrically before and after storage at $25{ }^{\circ} \mathrm{C}$ under conditions of various relative humidities $(5-98 \% \mathrm{RH})$ in hermetic systems for $7 \mathrm{~d}$. The various $\mathrm{RH}$ conditions were achieved using saturated salt solutions (Greenspan, 1977). The water sorption behaviour was evaluated from the average weight change at each storage time and was expressed as moisture increase per starting weight. The assay was performed in triplicate.

\section{Results and Discussion}

The flow of powder during manufacturing dictates the quality of the product in terms of its weight and content uniformity. However, the flow profile of a powder is complex and multidimensional, and it does in fact depend upon many powder characteristics. For this reason, no single test could ever quantify flowability (Prescott \& Barnum, 2000). To address this multivariate problem, several flow measurements were performed in order to obtain a more coherent flow classification.

The results for flowability and particles size of CA and MI commercially-dried extracts are shown in Table 2. Although these extracts have a use in 
phytotherapeutics, the low mean particle size favours the cohesive interparticle forces that lead to poor flow properties. These samples exhibited no free-flow through the standard funnel; therefore, the angle of repose was not determined, and the flow time was considered infinite.

The rheological behaviour of pharmaceutical excipients isolated also presented deficient flow properties (Table 2). These materials act as modifying agents that change the surface properties of pharmaceutical ingredients. In this study, it was expected that they could improve the mechanical behaviour of MI and CA extracts. The physical mixture of dried extract and excipient did not increase flow characteristics in any composition evaluated (data not shown). The heterogeneity of the samples, as well as their poor rheological behaviour, makes these materials unsuitable for a compression process.

Co-processing of vegetal extracts with pharmaceutical excipients could lead to the formation of materials with superior mechanical characteristics suitable for direct compression. The technique chosen to produce co-processed plant extract was agglomeration by wet granulation. A simplex lattice design was used in order to determine optimal formulation composition (Table 1). The results of flow parameters, particle size and bulk density are shown in Tables 3 and 4 .

In general, co-processing of both extracts demonstrated important enhancements in flow, bulk density and particle size behaviour. Several formulations presented clear evidence of flowability improvement: a compressibility index lower than $15 \%$ and a Hausner index below 1.18 (Tables 3 and 4). Furthermore, an angle of repose of approximately $35-40^{\circ}$ and a flow time of less than $15 \mathrm{~s}$ corroborate these favourable flow results.

The particle size analysis of co-processed extracts exhibited a normal and broad distribution, with values up to $700 \mu \mathrm{m}$. In contrast with dried extracts, coprocessed material had enlarged diameters, which would explain their better flow properties. Most of the particles fell within the range of 300-400 $\mu \mathrm{m}$. Notable differences were pointed out between co-processed extracts (Table 3 and 4). For both CA and MI extracts, with the increasing amount of MCC, the mean particle size decreased. The largest granules were obtained with the formulations containing lactose. This effect in mean particle size on account of granules formulations is described in literature (Rantanen et al., 2001).

The bulk density results revealed an important difference between the formulations, specifically the values situated in the range of 0.3 to $0.5 \mathrm{~g} / \mathrm{cm}^{3}$. This parameter has a special interest for plant extracts because of the high dose requirement and, in the case of tablets, a limitation due to the die diameter.

The experimental mixture design used in this stage of study provided a predictable equation for each mechanical parameter examined, according to a refined model (Tables 3 and 4). Most of the resultant equations obtained with CA co-processed presented coefficients with second and third order terms, indicating a high level of interaction between the excipients studied. The fitted model for flow time and bulk density is linear and shows that the interaction terms are insignificant. A linear fit was also found for most of the MI co-processed with the exception of compressibility and Hausner indices that presented significant second-order terms.

The refined model was used for drawing contour plots, as shown in Figures 1 and 2. The grey areas represent the proportions of $\mathrm{MCC}$, lactose and starch in the formulation that produced the best results. Similar profiles were found for both MI and CA extracts. It is noted from the contour plot that a higher amount of lactose produced the best flow results as well as a greater particle size and an increased bulk density, whereas MCC generated the least effect. Nevertheless, the addition of a small amount of starch and MCC can favour the mechanical properties of co-processed extracts and show a synergic effect.

The results are very clear in distinguishing formulations 3, 5 and 10 of both MI and CA as the best compositions for all mechanical parameters tested, and they were selected to be used in the compression phase of our study.

The mechanical characteristics of the tablets made with co-processed extracts are described in Figure 3. All selected formulations presented a good appearance and appropriate dimensions. None exhibited lamination or capping, indicating that air was not trapped inside the die, which is a common problem in tablet vegetal extract formulations (Soares et al., 2005). Tablet weight satisfactorily met pharmacopeial specifications

Table 2. Mechanical properties of MI and CA commercial-dried extracts, milling plants and the pharmaceutical excipients.

\begin{tabular}{|c|c|c|c|c|c|}
\hline \multicolumn{2}{|c|}{ Sample } & Compressibility index (\%) & Hausner index & Flow time $(\mathrm{s})$ & Mean particles size $(\mu \mathrm{m})$ \\
\hline \multirow{2}{*}{ Dried extracts } & MI & $31.0 \pm 0.0$ & $1.5 \pm 0.0$ & $\infty$ & $83.7 \pm 38.0$ \\
\hline & CA & $23.4 \pm 1.2$ & $1.3 \pm 0.0$ & $\infty$ & $81.6 \pm 32.8$ \\
\hline \multirow{3}{*}{ Excipients } & Starch & $37.0 \pm 1.0$ & $1.6 \pm 0.0$ & $\infty$ & - \\
\hline & $\mathrm{MCC}$ & $36.7 \pm 1.5$ & $1.5 \pm 0.0$ & $\infty$ & - \\
\hline & Lactose & $33.0 \pm 2.6$ & $1.5 \pm 0.1$ & $\infty$ & - \\
\hline
\end{tabular}


Table 3. Mechanical properties of CA co-processed extracts with the correspondent fit model and prediction equation for each parameter tested.

\begin{tabular}{|c|c|c|c|c|c|c|}
\hline Formulation & $\begin{array}{l}\text { Compressibility } \\
\text { index }(\%)\end{array}$ & Hausner index & $\begin{array}{c}\text { Angle of repose } \\
\left({ }^{\circ}\right)\end{array}$ & Flow time (s) & $\begin{array}{l}\text { Bulk density (g/ } \\
\mathrm{mL})\end{array}$ & $\begin{array}{c}\text { Mean particles } \\
\text { size }(\mu \mathrm{m})\end{array}$ \\
\hline 1 & $23.3 \pm 1.5$ & $1.30 \pm 0.03$ & $41.3 \pm 0.9$ & $9.7 \pm 0.2$ & 0.37 & $413.4 \pm 232.6$ \\
\hline 2 & $30.3 \pm 0.6$ & $1.44 \pm 0.01$ & $41.3 \pm 0.9$ & $9.5 \pm 0.1$ & 0.31 & $247.5 \pm 270.4$ \\
\hline 3 & $13.7 \pm 1.2$ & $1.16 \pm 0.01$ & $39.0 \pm 0.4$ & $7.2 \pm 0.1$ & 0.47 & $555.3 \pm 270.3$ \\
\hline 4 & $15.1 \pm 1.0$ & $1.18 \pm 0.01$ & $42.0 \pm 0.3$ & $8.6 \pm 0.2$ & 0.37 & $433.6 \pm 256.4$ \\
\hline 5 & $13.3 \pm 1.5$ & $1.15 \pm 0.02$ & $40.5 \pm 0.5$ & $7.8 \pm 0.3$ & 0.41 & $501.0 \pm 263.2$ \\
\hline 6 & $18.0 \pm 1.7$ & $1.22 \pm 0.03$ & $41.0 \pm 0.7$ & $8.3 \pm 0.1$ & 0.35 & $420.8 \pm 256.4$ \\
\hline 7 & $18.7 \pm 0.6$ & $1.23 \pm 0.01$ & $40.7 \pm 0.5$ & $8.2 \pm 0.2$ & 0.36 & $437.8 \pm 270.3$ \\
\hline 8 & $19.1 \pm 1.0$ & $1.23 \pm 0.02$ & $40.3 \pm 0.9$ & $8.1 \pm 0.1$ & 0.37 & $443.4 \pm 277.8$ \\
\hline 9 & $22.0 \pm 1.7$ & $1.28 \pm 0.03$ & $40.3 \pm 0.8$ & $8.7 \pm 0.3$ & 0.33 & $389.8 \pm 270.7$ \\
\hline 10 & $12.7 \pm 3.0$ & $1.15 \pm 0.04$ & $38.9 \pm 0.6$ & $7.9 \pm 0.2$ & 0.41 & $488.2 \pm 270.3$ \\
\hline Fit model & Special cubic & Special cubic & Linear & Linear & Quadratic & Quadratic \\
\hline $\begin{array}{c}\text { Predict } \\
\text { equation* }\end{array}$ & $\begin{array}{c}=+23 \cdot 8 \cdot X_{1} \\
+30.5 \cdot X_{2} \\
+13 \cdot 0 \cdot X_{3} \\
-46.1 \cdot X_{1} \cdot X_{2} \\
-21.2 \cdot X_{1} \cdot X_{3} \\
-17.1 \cdot X_{2} \cdot X_{3} \\
\quad+144.7 . \\
\quad X_{1} \cdot X_{2} \cdot X_{3}\end{array}$ & $\begin{array}{c}=+1.31 \cdot X_{1} \\
+1.44 \cdot X_{2} \\
+1.15 \cdot X_{3} \\
-0.75 \cdot X_{1} \cdot X_{2} \\
-0.32 \cdot X_{1} \cdot X_{3} \\
-0.33 \cdot X_{2} \cdot X_{3} \\
\quad+2.21 . \\
\quad X_{1} \cdot X_{2} \cdot X_{3}\end{array}$ & $\begin{array}{c}=+41.1 . X_{1} \\
+41.3 . X_{2} \\
+40.0 . X_{3}\end{array}$ & $\begin{array}{l}=+ \text { 8.9. } X_{1} \\
+ \text { 9.2. } X_{2} \\
+ \text { 7.1. } X_{3}\end{array}$ & $\begin{array}{l}=+0.37 \cdot X_{1} \\
+0.31 \cdot X_{2} \\
+0.47 \cdot X_{3} \\
+0.09 \cdot X_{1} \cdot X_{2} \\
-0.06 \cdot X_{1} \cdot X_{3} \\
-0.18 \cdot X_{2} \cdot X_{3}\end{array}$ & $\begin{array}{l}=+413 \cdot X_{1} \\
+254 \cdot X_{2} \\
+555 \cdot X_{3} \\
+372 \cdot X_{1} \cdot X_{2} \\
+12 \cdot X_{1} \cdot X_{3} \\
+39 \cdot X_{2} \cdot X_{3}\end{array}$ \\
\hline $\mathrm{R}^{2}$ & 0.91 & 0.96 & 0.62 & 0.66 & 0.97 & 0.96 \\
\hline APrecision & 13.0 & 19.5 & 6.4 & 8.6 & 27.3 & 25.0 \\
\hline
\end{tabular}

* $\mathrm{X}_{1}$ : starch, $\mathrm{X}_{2}: \mathrm{MCC}$ and $\mathrm{X}_{3}$ : lactose.

Table 4. Mechanical properties of MI co-processed extracts with the correspondent fit model and prediction equation for each parameter tested.

\begin{tabular}{ccccccc}
\hline Formulation & $\begin{array}{c}\text { Compressibility } \\
\text { index }(\%)\end{array}$ & Hausner index & $\begin{array}{c}\text { Angle of repose } \\
\left({ }^{\circ}\right)\end{array}$ & Flow time $(\mathrm{s})$ & $\begin{array}{c}\text { Bulk density }(\mathrm{g} / \\
\mathrm{mL})\end{array}$ & $\begin{array}{c}\text { Mean particles } \\
\text { size }(\mu \mathrm{m})\end{array}$ \\
\hline 1 & $17.3 \pm 0.6$ & $1.21 \pm 0.01$ & $38.0 \pm 1.0$ & $8.5 \pm 0.1$ & 0.39 & $495.0 \pm 277.8$ \\
2 & $18.0 \pm 1.0$ & $1.22 \pm 0.01$ & $40.6 \pm 2.3$ & $9.6 \pm 0.1$ & 0.32 & $475.2 \pm 263.2$ \\
3 & $14.0 \pm 1.0$ & $1.16 \pm 0.01$ & $37.0 \pm 1.4$ & $6.0 \pm 0.1$ & 0.50 & $494.6 \pm 303.0$ \\
4 & $15.0 \pm 2.0$ & $1.18 \pm 0.03$ & $39.0 \pm 0.7$ & $7.9 \pm 0.1$ & 0.39 & $480.3 \pm 294.1$ \\
5 & $12.6 \pm 1.5$ & $1.15 \pm 0.02$ & $37.0 \pm 1.7$ & $6.8 \pm 0.1$ & 0.46 & $503.3 \pm 294.1$ \\
6 & $17.0 \pm 1.3$ & $1.20 \pm 0.02$ & $39.0 \pm 1.2$ & $7.5 \pm 0.1$ & 0.40 & $490.8 \pm 277.8$ \\
7 & $14.3 \pm 0.3$ & $1.17 \pm 0.01$ & $37.7 \pm 0.9$ & $7.9 \pm 0.3$ & 0.41 & $501.9 \pm 285.7$ \\
8 & $15.7 \pm 0.5$ & $1.19 \pm 0.01$ & $36.0 \pm 0.4$ & $7.1 \pm 0.1$ & 0.43 & $490.0 \pm 312.5$ \\
9 & $14.7 \pm 1.5$ & $1.17 \pm 0.02$ & $38.6 \pm 1.6$ & $8.5 \pm 0.0$ & 0.36 & $480.1 \pm 270.3$ \\
10 & $14.7 \pm 1.2$ & $1.17 \pm 0.02$ & $36.6 \pm 1.5$ & $6.8 \pm 0.2$ & 0.44 & $515.5 \pm 303.0$ \\
\hline Fit model & Quadratic & Quadratic & Linear & Linear & Linear & Linear \\
\hline & $=+17.6 . \mathrm{X}_{1}$ & $=+1.21 . \mathrm{X}_{1}$ & $=+37.0 . \mathrm{X}_{1}$ & $=+7.8 . \mathrm{X}_{1}$ & $=+0.41 . \mathrm{X}_{1}$ & $=+496 . \mathrm{X}_{1}$ \\
& $+17.6 . \mathrm{X}_{2}$ & $+1.21 . \mathrm{X}_{2}$ & $+40.2 . \mathrm{X}_{2}$ & $+9.2 . \mathrm{X}_{2}$ & $+0.32 . \mathrm{X}_{2}$ & $+475 . \mathrm{X}_{2}$ \\
Predict & $+14.2 . \mathrm{X}_{3}$ & $+1.16 . \mathrm{X}_{3}$ & $+36.5 . \mathrm{X}_{3}$ & $+6.0 . \mathrm{X}_{3}$ & $+0.49 . \mathrm{X}_{3}$ & $+507 . \mathrm{X}_{3}$ \\
equation* & $-10.8 . \mathrm{X}_{1} \cdot \mathrm{X}_{2}$ & $-0.14 . \mathrm{X}_{1} \cdot \mathrm{X}_{2}$ & & & & \\
\hline APrecision & $-11.2 . \mathrm{X}_{1} \cdot \mathrm{X}_{3}$ & $-0.13 . \mathrm{X}_{1} \cdot \mathrm{X}_{3}$ & & & & \\
\hline
\end{tabular}

$* \mathrm{X}_{1}$ : starch, $\mathrm{X}_{2}$ : MCC and $\mathrm{X}_{3}$ : lactose. 
(maximum variation of 5\%) and the low relative standard deviation values indicated favourable feeding conditions allowed by the improved flowability of co-processed extracts.

Adequate hardness was obtained for most of the formulations. However, formulation number 5 containing CA did not produce hard tablets, as evinced by a hardness under the minimum $3 \mathrm{kgF}$ required. In addition, some problems were found with the friability of formulation 3 containing CA and formulations 5 and 10 made with MI extracts; those tablets showed weight loss values higher than $1.5 \%$. All tablets disintegrated rapidly, fulfilling compendia requirements. The high values of hardness for some samples did not affect this parameter.

Accordingly, CA formulation 10 and $\mathrm{MI}$ formulation 3 passed all quality control assays and were selected for the hygroscopicity study.

The sorption isotherms were drawn by determining the equilibrium moisture content at different relative humidities for selected tablets of $\mathrm{MI}$ and $\mathrm{CA}$ and by comparing them with the commercially-dried extracts placed inside a gelatine capsule (Figure 4). According to the Callahan classification (Callahan et al., 1982) all samples evaluated are moderately hygroscopic. This behaviour corroborates the known high sensitivity of dried vegetal extracts to atmospheric humidity (Palma et al., 2002; Souza et al., 2007). However marked differences in moisture sorption properties between tablets and capsules were noted.
As expected, gelatine capsules containing extracts were found to be quite sensitive to variations in RH. For both extracts, capsules became brittle in low RH atmosphere and showed softening in high RH environment. On the other hand, the co-processed extract in tablet form seemed to protect the vegetal extract from atmospheric moisture by keeping the level of humidity inside the samples low. This effect may be attributed to the agglomeration and compaction processes that reduce the specific surface of material and make the vegetal tablets more resistant to water incorporation. The physical aspects of tablets remained unchanged during the hygroscopicity assay. Only in high RH conditions was an increase in the moisture of tablet samples observed.

In conclusion, this study demonstrated that coprocessing is a feasible technique to overcome the poor flowability of vegetal extracts. The use of experimental design provided a full understanding of powder-flow properties and may lead to the selection of formulations with better properties and with the least expenditure of time and materials. The contour plots revealed that formulations with a higher amount of lactose produced the best flow results as well as a larger particle size and a greater bulk density. Tablets elaborated with formulation 3 containing MI co-processed extracts and formulation 10 containing CA co-processed extracts presented the best results of quality control. Those tablets showed appropriate physical-chemical characteristics and revealed a more stable moisture sorption behaviour compared to commercial gelatine capsules.

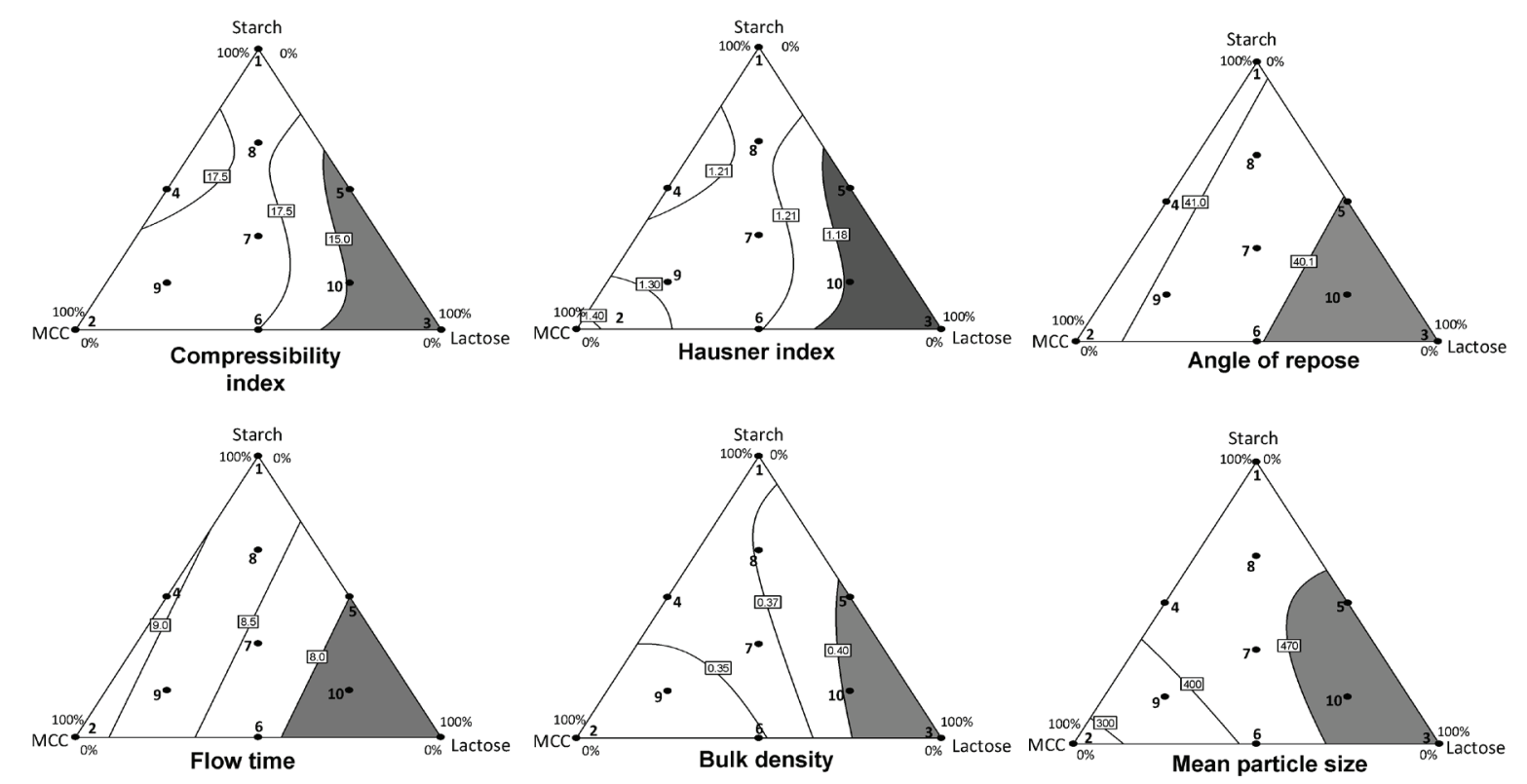

Figure 1. Contour diagrams of co-processed CA extracts with the experimental points. Each contour represents a constant response factor. Grey areas show regions where mixture composition had the best response. 


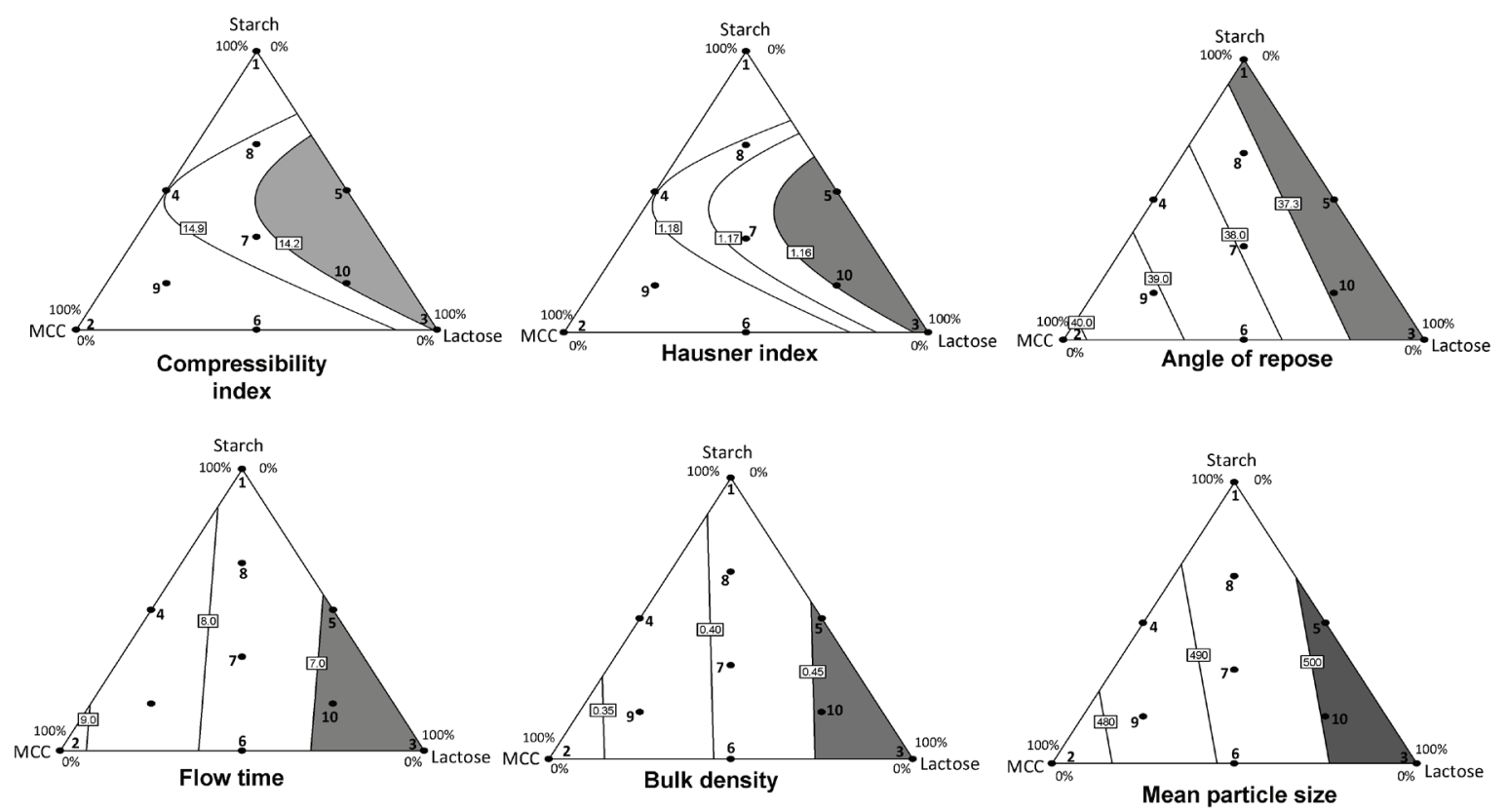

Figure 2. Contour diagrams of co-processed MI extracts with the experimental points. Each contour represents a constant response factor. Grey areas show regions where mixture composition had the best response.
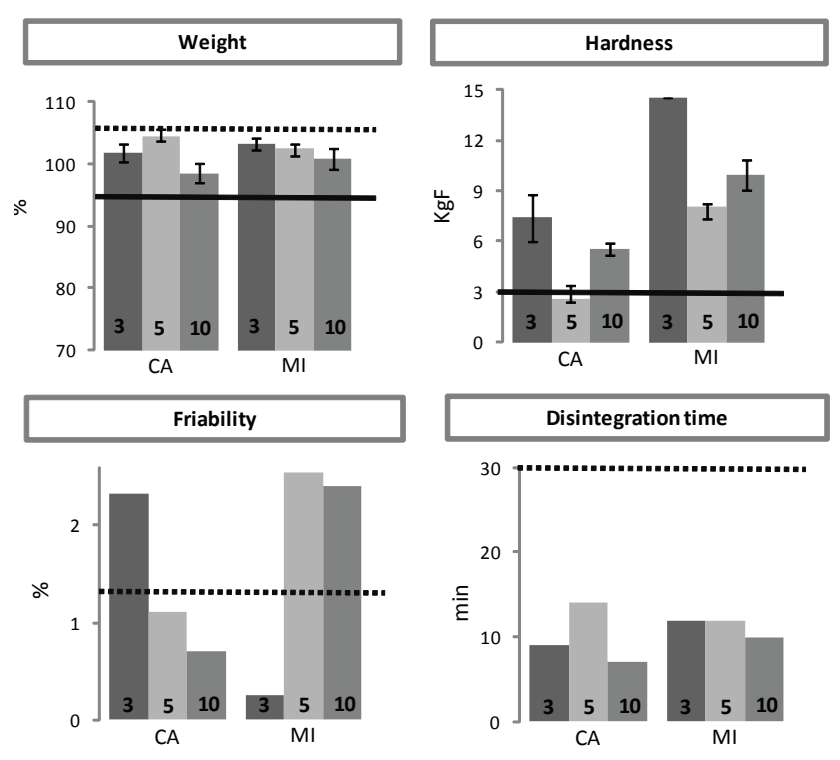

Figure 3. Quality control results of tablet formulations containing CA and MI extracts. The continuous line and the dotted line indicate the minimum and maximum limits established by Pharmacopoeia, respectively.

\section{Acknowledgements}

Authors thank the $\mathrm{CNPq} /$ Brazil and Federal University of Ouro Preto, Brazil, for the financial support.
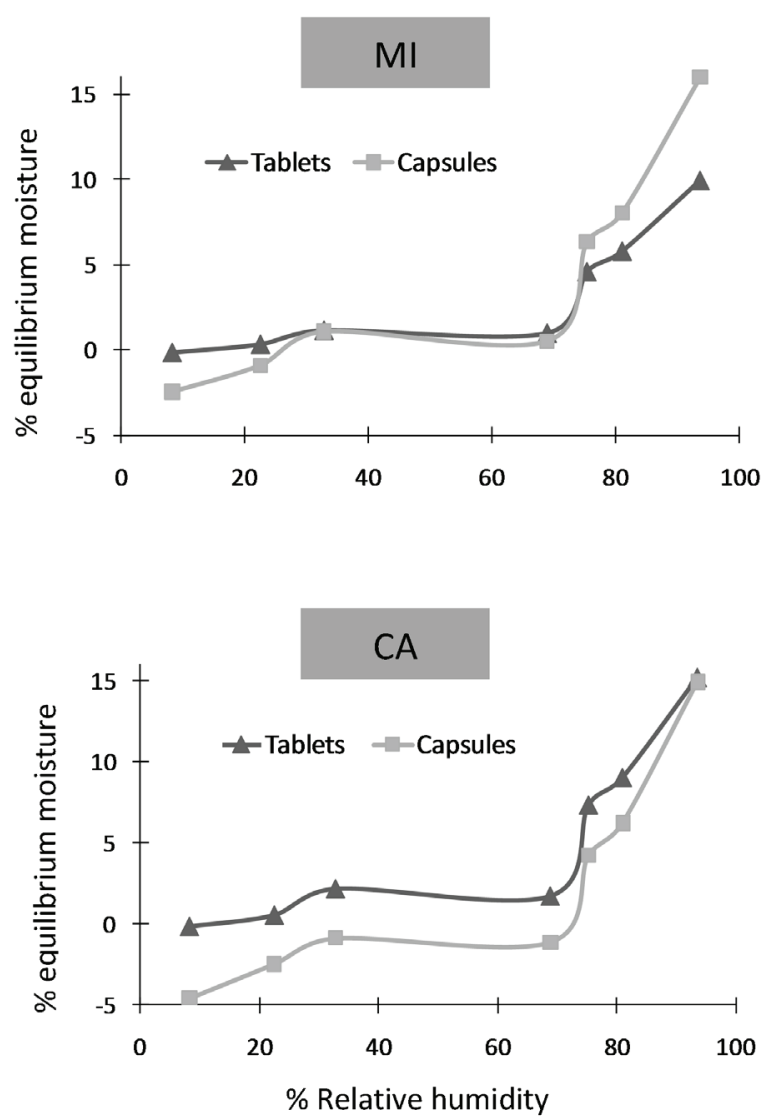

Figure 4. Sorption isotherms of tablets and hard gelatine capsules containing $\mathrm{CA}$ and $\mathrm{MI}$ extracts. 


\section{References}

Anderson MJ, Whitcomb PJ 2005. RSM Simplified: optimizing processes using response surface methods for design of experiments. New York: Productivity Press.

Callahan JC, Cleary GW, Elefant M, Kaplan G, Kensler T, Nash RA 1982. Equilibrium moisture content of pharmaceutical excipients. Drug Dev Ind Pharm 8: 355-369.

Carr RL 1965. Evaluation of flow properties of solids. Chem Eng $J$ 72: 163-168.

Cunha-Filho MSS, Sá-Barreto LCL 2009. Excipientes coprocessados para compressão direta de comprimidos. Lat Am J Pharm 28: 304-312.

Gohel MC, Jogani PD 2005. A review of co-processed directly compressible excipients. J Pharm Pharm Sci 8: 76-93.

Greenspan L 1977. Humidity fixed points of binary saturated aqueous solutions. J Res Nat Bur Stand Sect A Phys Chem 81A: 89-96.

Oliveira OW, Petrovick PR 2010. Secagem por aspersão (spray drying) de extratos vegetais: bases e aplicações. Rev Bras Farmacogn 20: 641-650.

Palma S, Luján C, Llabot JM, Barbosa G, Manzo RH, Allemandi DA 2002. Design of Peumus boldus tablets by direct compression using a novel dry plant extract. Int $J$ Pharm 233: 191-198.

Pasqualoto KFM, Funck JAB, Silva FEB, Kratz CP 2005. Utilização de probitos como instrumento estatístico simples à avaliação da distribuição de tamanho de partícula de dois tipos de celulose microcristalina. Rev Bras Farm 86: 31-34.

Prescott JK, Barnum RA 2000. On powder flowability. Pharm Tech Oct October: 60-85.

Rantanen J, Jørgensen A, Räsänen E, Luukkonen P, Airaksinen, S, Raiman J, Hänninen K, Antikainen O, Yliruusi J 2001. Process analysis of fluidized bed granulation. AAPS PharmSciTech 2: article 21.

Real Farmacopea Española 2005. 3. ed. Madrid: Ministerio de Sanidad y Consumo.

Santos-Oliveira R, Coulaud-Cunha S, Colaço W 2009. Revisão da Maytenus ilicifolia Mart. ex Reissek, Celastraceae. Contribuição ao estudo das propriedades farmacológicas. Rev Bras Farmacogn 19: 650-659.

Silva CR, Monteiro MR, Caldeira-de-Araújo A, Bezerra RJAC 2004. Absence of mutagenic and citotoxic potentiality of senna (Cassia angustifolia Vahl.) evaluated by microbiological tests. Rev Bras Farmacogn 14: 01-03.

Soares LAL, Ortega GG, Petrovick PR, Schmidt PC 2005.

Dry granulation and compression of spray-dried plant extracts. AAPS PharmSciTech 6: E359-E366.

Souza TP, Martínez-Pacheco R, Gómez-Amoza JL, Petrovick PR 2007. Eudragit E as excipient for production of granules and tablets from Phyllanthus niruri L spraydried extract. AAPS PharmSciTech 8: E54-E60.

Spaniol B, Bica VC, Ruppenthal LR, Volpato MR, Petrovick PR 2009. Compressional behavior of a mixture of granules containing high load of Phyllanthus niruri spraydried extract and granules of adjuvants: Comparison between eccentric and rotary tablet machines. AAPS PharmSciTech 10: 1013-1023.

Staniforth JN 2005. Fluxo de pós. In Aulton ME (org.). Delineamento de formas farmacêuticas. 2. ed. Porto Alegre: Artmed, p. 208-221.

World Health Organization 2007. Guidelines for assessing quality of herbal medicines with reference to contaminants and residues. Switzerland: World Health Organization.

United States Pharmacopeia 2008. 30. ed. Rockville: United States Pharmacopeial Convention.

Veiga Junior VF 2008. Estudo do consumo de plantas medicinais na Região Centro-Norte do Estado do Rio de Janeiro: aceitação pelos profissionais de saúde e modo de uso pela população. Rev Bras Farmacogn 18: 308-313.

Vieira SC, Heredia SS, Vieira MC, Zárate NAH 2010. Levantamento de fitoterápicos manipulados em farmácias magistrais de Dourados-MS. Rev Bras Farmacogn 20: 28-34.

Zhao X, Du F, Zhu Q, Qiu D, Yin W, Ao Q 2010. Effect of superfine pulverization on properties of Astragalus membranaceus powder. Powder Technol 203: 620-625.

\section{*Correspondence}

Marcílio S. S. Cunha-Filho

Instituto de Ciências da Saúde, Campus Universitário de Sinop, Universidade Federal do Mato Grosso

Av. Alexandre Ferronato, 1200, Reserva 35, Setor Industrial, 78557-267 Sinop-MT, Brazil

marcilio.cunha@pq.cnpq.br

Tel. +556635317679

Fax: +556635319797 